\title{
Non-linear analysis of pile groups subjected to lateral loads using ' $p-y$ ' curve
}

\author{
H.S. Chore*1, R.K. Ingle ${ }^{2}$ and V.A. Sawant ${ }^{3}$ \\ ${ }^{1}$ Department of Civil Engineering, Datta Meghe College of Engineering, \\ Sector-3, Airoli, Navi Mumbai- 400 708, India \\ ${ }^{2}$ Department of Applied Mechanics, Visvesvaraya National Institute of Technology (VNIT), \\ Nagpur- 440 010, India \\ ${ }^{3}$ Department of Civil Engineering, Indian Institute of Technology (IIT), Roorkee-247 667, India
}

(Received January 17, 2012, Revised February 21, 2012, Accepted February 22, 2012)

\begin{abstract}
The paper presents the analysis of two groups of piles subjected to lateral loads incorporating the non-linear behaviour of soil. The finite element method is adopted for carrying out the parametric study of the pile groups. The pile is idealized as a one dimensional beam element, the pile cap as two dimensional plate elements and the soil as non-linear elastic springs using the $p-y$ curves developed by Georgiadis et al. (1992). Two groups of piles, embedded in a cohesive soil, involving two and three piles in series and parallel arrangement thereof are considered. The response of the pile groups is found to be significantly affected by the parameters such as the spacing between the piles, the number of piles in a group and the orientation of the lateral load. The non-linear response of the system is, further, compared with the one by Chore et al. (2012) obtained by the analysis of a system to the present one, except that the soil is assumed to be linear elastic. From the comparison, it is observed that the non-linearity of soil is found to increase the top displacement of the pile group in the range of $66.4 \%-145.6 \%$, while decreasing the fixed moments in the range of $2 \%$ to $20 \%$ and the positive moments in the range of $54 \%$ to $57 \%$.
\end{abstract}

Keywords: laterally loaded piles; winkler's foundation; modulus of subgrade reaction; $p-y$ curve; nonlinear spring.

\section{Introduction}

Pile foundations are generally preferred when heavy structural loads have to be transferred through weak subsoil to firm strata. Besides vertical loads, these foundations in some situations are subjected to a significant amount of lateral loads, which may be due to impact of ships during berthing or wave actions for off-shore structures. Pile supported foundations of earth retaining walls and transmission tower structures will also be subjected to lateral loads. Building frames supported by pile foundations exposed to wind loads also fall under the category of the structures/substructures subjected to lateral loads. The problem of laterally loaded piles or pile group involves particularly the complex soil-structure interaction between the piles and pile cap.

\footnotetext{
* Corresponding author, Ph.D., E-mail: hschore@rediffmail.com
} 
Two conventional approaches exist for analyzing laterally loaded piles, including the elastic continuum approach (Banerjee and Davis 1978, Poulos 1971) and the modulus of subgrade reaction approach (Matlock and Reese 1956, Geogiadis and Butterfield 1982). In the last three decades we have witnessed a tremendous growth in the numerical methods and it is now possible to obtain a more realistic and satisfactory solution for any soil-structure related problems. Among these methods, the most versatile, prominent and successful procedure is the finite element method, which overcomes the drawbacks of the conventional approaches. Many studies were reported in the literature, including those by Desai and Appel (1976), Desai et al. (1981), Dewaikar et al. (2007), Chore et al. (2010).

Though most of the analyses consider the behaviour of soil as linear, in practice the soil behaves in the non-linear fashion. The non-linear behaviour of soil can be represented by three dimensional constitutive models; but this will be expensive in terms of computational resources and memory requirement. The subgrade reaction approach has been widely used due to its simplicity (Reese and Matlock 1956). This approach treats a laterally loaded pile as a beam on elastic foundation. The soil behaviour is modeled by Winkler's hypothesis (Fig. 1), by which the pressure $(p)$ and deflection $(y)$ at a point of the pile are related by the modulus $K_{h}$ of subgrade reaction as horizontal spring, namely, $p=K_{h} . y$, where $K_{h}$ has the unit of force/ length ${ }^{3}$.

The $p-y$ approach is the most commonly used method since it can account for factors such as nonlinearity and soil layering (Matlock 1970). The $p-y$ curve approach has been adopted by several researchers to analyze laterally loaded piles or group thereof (Reese et al. 1974, Georgiadis et al. 1992, Sawant et al. 1996, Broms and Choa 1998, Mocwa and Duncan 2001, Dewaikar and Patil 2006, Chiou and Chen 2007, Kim et al. 2009, Dewaikar et al. 2009, Kodikara et al. 2010, Kim et al. 2011, Dewaikar et al. 2011).

The non-linear analysis of the laterally loaded pile group is reported in the present paper. The finite element analysis procedure is adopted in the parametric study of two pile groups comprising either two and three piles. Further, two arrangements of piles in a group are considered with reference to the lateral load acting on the pile cap. Linear elastic behaviour is assumed for the elements of the pile group such as pile and pile cap, whereas the behaviour of soil is assumed to be non-linear-elastic. The pile is modeled as a one dimensional beam element, the pile cap as a two dimensional plate element, and the soil as the non-linear elastic springs using the $p-y$ curves proposed by Georgiadis et al. 1992). The response obtained in the present study is compared with

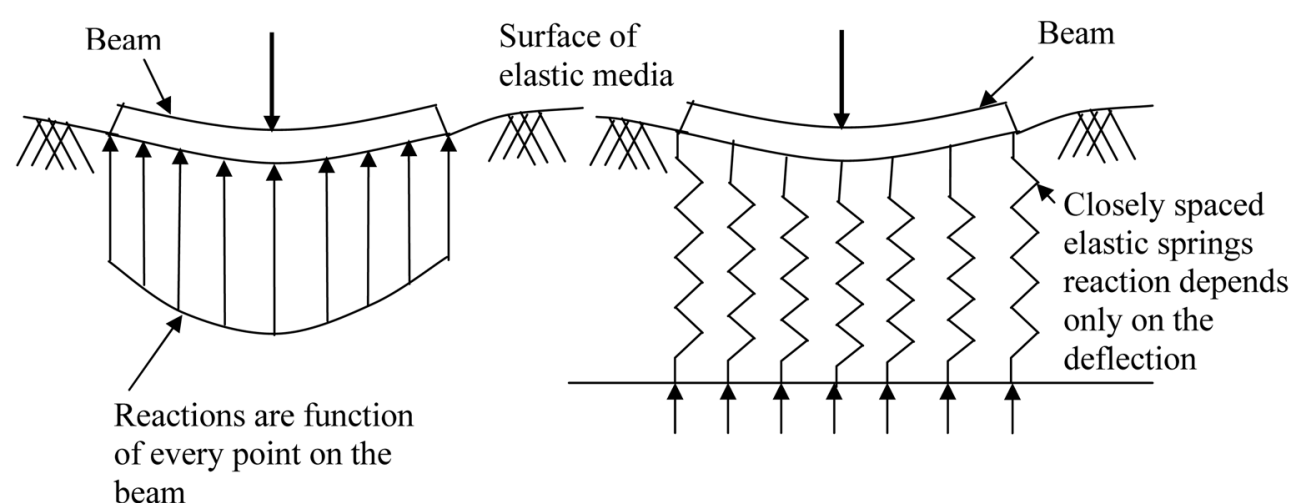

Fig. 1 Winkler's hypothesis 


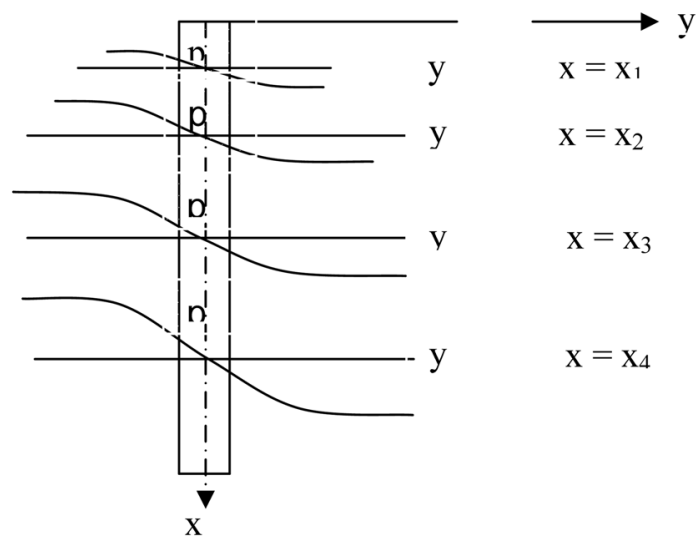

Fig. 2 Family of $p-y$ curves

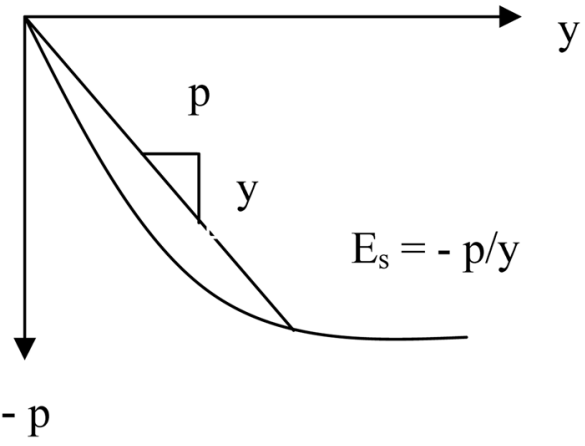

Fig. 3 Illustration of the secant modulus

the linear analysis result by Chore et al. (2012) for the same system, but with the soil assumed to be linear elastic.

\section{2. $p-y$ analysis}

A family of $p-y$ curves is shown in Fig. 2, in which each curve represents the soil behaviour at a different depth. For convenience, a secant modulus of soil reaction, $E_{s}$, as illustrated in Fig. 3 is often used.

$$
E_{s}=\frac{p}{y}
$$

in which $y$ is the pile deflection and $p$ the soil reaction expressed as the force per unit length of the pile. The value of $E_{\mathrm{s}}$ can vary in any arbitrary manner with depth and with deflection.

In general, the relation between the soil pressure and deflection at any point along a pile is nonlinear as shown in Fig. 3. The solution requires a series of $p-y$ curves for various points along the pile. Such a set of $p-y$ curves is shown schematically in Fig. 2, which implies that the behaviour 
of the soil at a particular depth is independent of its behaviour at the other locations, while may not be strictly true. The key to the solution of laterally loaded piles lies in the construction of the $p-y$ curves, which depend upon factors such as depth, type of soil and deformations.

On the basis of the experiments, Reese et al. (1974) observed that the above assumption is sufficiently true for practical purposes. Since there is no restriction on the shape of the $p-y$ curves, an iterative solution using the finite difference formulation is necessary to obtain compatible values of $p$ and $y$ at all points along the pile.

The analysis of pile behaviour using the subgrade reaction approach requires knowledge of variation of $K_{h}$ along the pile length. Reese and Matlock (1956) employed the finite difference scheme for the case of subgrade modulus varying linearly with depth. Georgiadis et al. (1992) proposed a set of $p-y$ curves for a laterally loaded pile embedded in soft clay. The significance of this method is that it includes the number of loading cycles $(N)$ and the initial slope of the $p-y$ curve is finite as compared to that of an infinite value given by Matlock's equations (1970).

In view of this, an effort is made in the present investigation to analyze the pile groups subjected to lateral loads using the $p-y$ curves along the lines as those of Georgiadis et al. (1992).

\section{Georgiadis' model}

Georgiadis et al. (1992) conducted a series of model tests on instrumented piles to study the pile response under the static and cyclic lateral loads in soft clay. The results were analyzed to determine appropriate load-displacement relationship for the non-linear springs ( $p$ - $y$ curves).

For static loading the hyperbolic function, which is widely used in stress-strain soil problems was found to fit remarkably well the data points. This method, as given below, approximates the empirical results much better than the empirical curve proposed by Matlock (1970).

$$
p=\frac{y}{\left[\left(\frac{1}{k}\right)+\left(\frac{y}{p_{u}}\right)\right]}
$$

where $k$ is the initial stiffness of the $p-y$ curve and $p_{u}$ is the ultimate soil resistance. The parameter $k$ in equation is a function of the basic elastic soil properties, diameter of pile and flexural stiffness. As was mentioned, the above expression gives a better approximation, i.e., a finite value, for the initial stiffness of the $p-y$ curves, as can be checked by $d p / d y=k$ for $y=0$.

The ultimate resistance of soil $\left(p_{u}\right)$ is expressed as

$$
p_{u}=N_{P} c_{u} d
$$

Here $N_{P}$ is non-dimensional coefficient, which increases with depth $(x)$, starting with an initial value of 3 at ground level to a maximum value of 9 as given below

$$
N_{P}=3+\left(\frac{\gamma x}{c_{u}}\right)+J\left(\frac{x}{d}\right)
$$

where $c_{u}=$ un-drained cohesion of soil,

$d=$ pile diameter, 
$\gamma=$ effective unit weight of the soil and

$J=$ empirical constant $=0.14$

$x=$ depth of soil under consideration

It was found by Georgiadis et al. (1992) that Eq. (2) approximates the test results much better than the empirical curve proposed by Matlock (1970), the main reason for this being the different initial stiffness of the two $p-y$ curves. Eq. (2) corresponds to elastic soil properties $(d p / d y=k$, for $y=0)$ while in Matlock's curve, the initial stiffness is infinite $(d p / d y=$ infinity, for $y=0)$. This infinite initial stiffness results in erroneous pile responses at the lower part of the pile where the soil resistance and displacements are small.

\section{Details of the finite element modeling}

\subsection{Beam element}

The beam or beam-column element adopted herein has six degrees of freedom at each node, which include the lateral displacement $u$ and $v$, axial displacement $w$ and rotation about the three axes (Fig. 4).

If the rotation about the $z$-axis is not considered, number of degrees of freedom is reduced to 5 . In this case, the nodal displacement vector $\{\delta\}_{e}$ is

$$
\{\delta\}_{e}^{T}=\left\{u_{1} v_{1} w_{1} \theta_{x 1} \theta_{y 1} u_{2} v_{2} w_{2} \theta_{x 2} \theta_{y 2}\right\}
$$

The stiffness matrix of the element, $[k]_{e}$, is given by

$$
[k]_{e}=\int_{0}^{L}[B]^{T}[D][B] d z
$$

where $[B]$ is the strain-displacement relation matrix and $[D]$ is the constitutive matrix for the beam element.

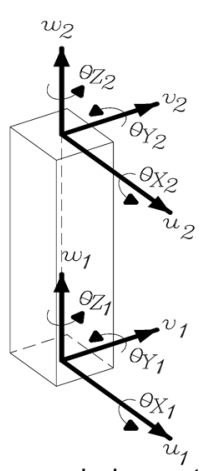

(a) General element

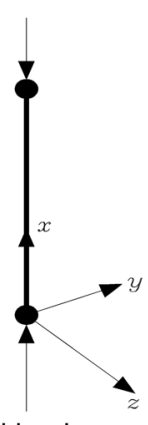

(b) Axial load

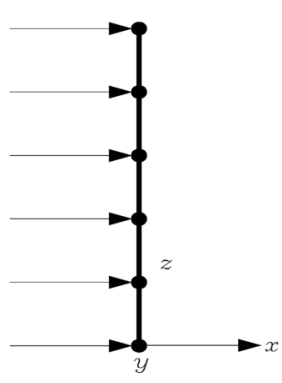

(c) Bending in $x$ direction

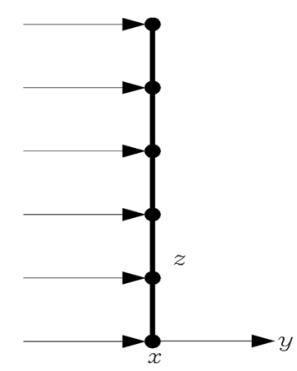

(d) Bending in y direction

Fig. 4 General beam-column element [After Desai et al. (1981)] 


\subsection{Spring element}

The soil support at various nodes of the beam elements is simulated by a series of equivalent and independent elastic springs in the three directions $(X, Y$ and $Z)$. The soil stiffness can be found out using principle of virtual work. A virtual displacement $\{\Delta d\}$ is applied to the spring system and by equating the internal work done to the external work, the soil stiffness can be determined. The soil reactions at any point $\left\{p_{x}, p_{y}\right.$ and $\left.p_{z}\right\}$ within each element are given by

$$
\left\{\begin{array}{l}
p_{x} \\
p_{y} \\
p_{z}
\end{array}\right\}=\left[\begin{array}{ccc}
E_{s x} & 0 & 0 \\
0 & E_{s y} & 0 \\
0 & 0 & E_{s z}
\end{array}\right]\left\{\begin{array}{l}
u \\
v \\
w
\end{array}\right\}
$$

where $\left\{E_{\mathrm{sx}}, E_{\mathrm{sy}}\right.$ and $\left.E_{\mathrm{sz}}\right\}$ are the soil subgrade reaction modulus at depth $z$.

The soil support element stiffness matrix, $[K]_{s}$, can be obtained as

$$
[K]_{s}=\int_{0}^{L}[N]^{T}\left[\begin{array}{ccc}
E_{s x} & 0 & 0 \\
0 & E_{s y} & 0 \\
0 & 0 & E_{s z}
\end{array}\right][N] d z
$$

\subsection{Plate element}

The pile cap is modeled using the 4 node element shown in Fig. 5. The lateral displacements $u$ and $v$ in the $x$ and $y$ directions are related to the membrane effect. To consider the bending aspect, three degrees of freedom are considered at each node, namely, the transverse displacement $w$, and the rotations about $x$ and $y$ axes, $\theta_{\mathrm{x}}$ and $\theta_{y}$. Together with two in-plane displacements, $u$ and $v$, there is a total of 5 degrees of freedom at each node. The number of degrees of freedom for the beam element and the plate element is the same. Consequently, the requirement of interelement compatibility between adjacent plate and beam elements can be taken care of.

\subsubsection{Membrane effect}

For the in-plane or membrane action of the plate, the plane stress idealization is considered. The
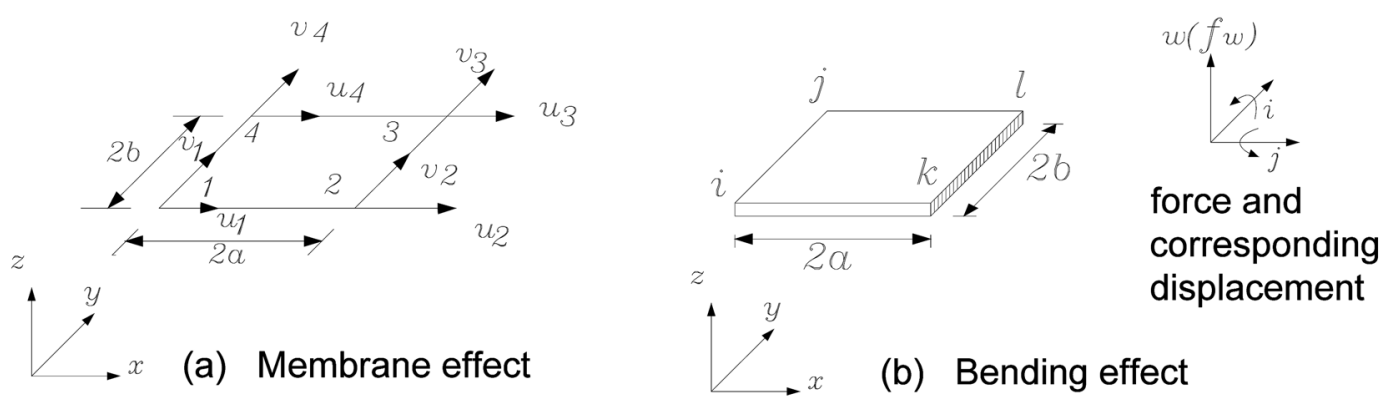

Fig. 5 General plate element [After Zienkiewicz (1977)] 
nodal displacement vector, $\{\delta\}^{T}$, is given by

$$
\{\delta\}^{T}=\left\{u_{1}, v_{1}, u_{2}, v_{2}, u_{3}, v_{3}, u_{4}, v_{4}\right\}
$$

The element stiffness matrix, $[k]_{i n}$, is given by

$$
[k]_{i n}=a b h \int_{-1-1}^{1} \int_{-1}^{1}[B]^{T}[D][B] d \xi d \eta
$$

where $[B]$ is the strain-displacement relation matrix, $[D]$ is constitutive matrix and $h$ represents the thickness of the element. The integration is carried out numerically with respect to $\xi$ and $\eta$, using the Gauss quadrature.

\subsection{Bending effect}

The nodal displacement vector $\{\delta\}$ of the plate element consists of 12 displacements given as

$$
\{\delta\}^{T}=\left\{\begin{array}{llll}
\delta_{1} & \delta_{2} & \delta_{3} & \delta_{4}
\end{array}\right\} \quad \text { and } \quad\{\delta\}^{T}=\left\{w_{1} \theta_{x i} \theta_{y i}\right\}
$$

Transverse displacement, $w$, is expressed in terms of the polynomial in $x$ and $y$ as

$$
\begin{gathered}
w=\alpha_{1}+\alpha_{2} x+\alpha_{3} y+\alpha_{4} x^{2}+\alpha_{5} x y+\alpha_{6} y^{2}+\alpha_{7} x^{3}+\alpha_{8} x^{2} y+\alpha_{9} x y^{2}+\alpha_{10} y^{3}+\alpha_{11} x^{3} y+\alpha_{12} x y^{3} \\
w=[P]\{\alpha\} \text { and }[P]=\left[\begin{array}{llll}
1 & x & y & x^{2} x y y^{2} x^{3} x^{2} y x y^{2} y^{3} x^{3} y x y^{3}
\end{array}\right]
\end{gathered}
$$

where $\{a\}$ is a constant vector composed of $\alpha_{1}$ to $\alpha_{12}$.

The rotations $\theta_{x}$ and $\theta_{y}$ are then given by

$$
\begin{aligned}
& \theta_{x}=\frac{\partial w}{\partial y}=\alpha_{3}+\alpha_{5} x+2 \alpha_{6} y+\alpha_{8} x^{2}+2 \alpha_{9} x y+3 \alpha_{10} y^{2}+\alpha_{11} x^{3}+3 \alpha_{12} x y^{2} \\
& \theta_{y}=\frac{\partial w}{\partial x}=\alpha_{2}+2 \alpha_{4} x+\alpha_{5} y+3 \alpha_{7} x^{2}+2 \alpha_{8} x y+\alpha_{9} y^{2}+3 \alpha_{11} x^{2} y+\alpha_{12} y^{3}
\end{aligned}
$$

The constants $a_{1}$ to $a_{12}$ can be evaluated by writing down 12 simultaneous equations for $w, \theta_{x}$ and $\theta_{y}$ at the 4 nodes of the element by substituting appropriate values of the coordinates $x$ and $y$. These twelve equations can be written in following way

$$
\{\delta\}=[C]\{\alpha\}
$$

where $[C]$ is a matrix defining the relationship between the displacements and constants $\alpha_{i}$. The element stiffness matrix, $[K]_{b d}$, for bending of the plate can be written as

$$
[K]_{b d}=\int_{-b-a}^{b} \int_{-a}^{a}[B]^{T}[D][B] d x d y
$$

where $[B]$ is the strain-displacement relation matrix for bending of the plate and $[D]$ is the constitutive matrix. 
For uniformly distributed load $q$ acting on the element, the load vector $[F]$ can be obtained as

$$
\{F\}=\left[C^{-1}\right]^{T} \int_{-b-a}^{b} \int_{a}^{a}[P]^{T} q d x d y
$$

\subsection{Method of analysis}

The stiffness matrices for the pile, soil and pile cap are assembled to yield the global stiffness matrix. From the assembled global stiffness matrix and load vector, the overall equilibrium equations are formulated for the system, from which the unknown nodal displacements are solved by Gauss elimination.

Back calculation of internal forces: After the nodal displacements are made available, the stiffness matrix of each element is recalled to get the internal forces $\{F\}_{e}$, such as the axial force, shear force and bending moment, for each element.

$$
\{F\}_{e}=[k]_{e}\{\delta\}_{e}
$$

\section{Non-linear soil structure interaction}

Even though in most previous studies, the soil is idealized as a linear elastic material, but for a he realistic analysis, the non-linear behaviour of soil should be considered. Based on Georgiadis' model (1992), an analysis program is developed in FORTRAN-90. The pile is idealized as one dimensional beam element, the pile cap as two dimensional plate element and the soil as springs as mentioned in the previous section. However, to account for the non-linear behaviour of soil, spring elements are modified according to the $p-y$ curves using an incremental approach. Fig. 6 illustrates the procedure commonly adopted to account for the non-linear behaviour by the incremental approach.

In the present analysis, the load is applied step-by-step with equal increment $\Delta P$. For each increment, linear analysis is carried out based on the tangent modulus $d p / d y$, by which the incremental displacement $\Delta y_{i}$ is obtained. For the first increment, the soil stiffness is set equal to the initial tangent modulus $k$, and in the successive increments it is treated as a function of the pressure and displacement $y_{i}$ accumulated up to the last increment. The derivative of the $p-y$ relationship is used for updating the soil moduli $E_{s x}, E_{s y}$ and $E_{s z}$ in Eq. (7) for each increment of load.

$$
\frac{d p}{d y}=\frac{k\left(1-\frac{p}{p_{u}}\right)}{1+\frac{k y}{p_{u}}}
$$

After each increment, the displacements generated at that increment are added to the existing displacements to yield the total displacements, $y_{i}$, caused by the total current load

$$
y_{i}=y_{i-1}+\Delta y_{i}
$$




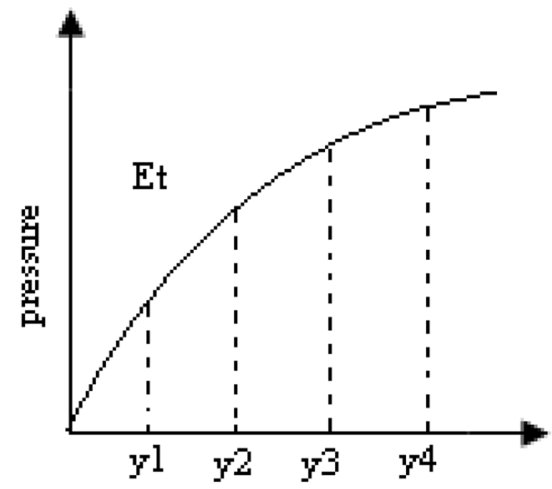

Fig. 6 Incremental approach

After computing the displacements, the corresponding pressures and derivative are evaluated using the above equations, and then used in the next increment. The next increment is applied again and the procedure is repeated.

\section{Assessment of accuracy of the numerical procedure}

The accuracy of the numerical procedure developed in the present study based on the Georgiadis' model is validated through comparison with the few works reported in the literature (Georgiadis et al. 1992, Rajashree and Sundaravadivelu 1999).

\subsection{Example 1 (Georgiadis et al. 1992)}

Georgiadis et al. (1992) carried out a series of model pile tests on an aluminium tubular pile of length $500 \mathrm{~mm}$ embedded in soft to medium clay $\left(\gamma=17.2 \mathrm{kPa}\right.$, undrained shear strength $C_{u}=28$ $\mathrm{kPa}$ ) for studying the non-linear response of the pile subjected to lateral loads in soft clay. Numerical analysis was performed wherein the pile was treated as an elastic beam on non-linear springs by the concept of $p-y$ curves.

A comparison by Georgiadis et al. (1992) between the measured and predicted pile responses indicates remarkably good agreement between the measurement and prediction. Fig. 7 shows the load-displacement relationship and Fig. 8 the distribution of moments along the depth of pile, indicating that the present solutions agree generally with those by Georgiadis et al. (1992). The difference observed between the responses by present procedure and those by Georgiadis et al. (1992) analytically is in the range of $3 \%$ to $8 \%$. And the difference in the present response and the one reported experimentally is in the range of $0.6 \%$ to $8 \%$. This validates the accuracy of the proposed method.

\subsection{Example 2 (Rajashree and Sundaravadivelu 1999)}

Rajashree and Sundaravadivelu (1999) described the computational procedure using the finite element method for finding out the effect of soil-pile separation and degradation of soil on non- 


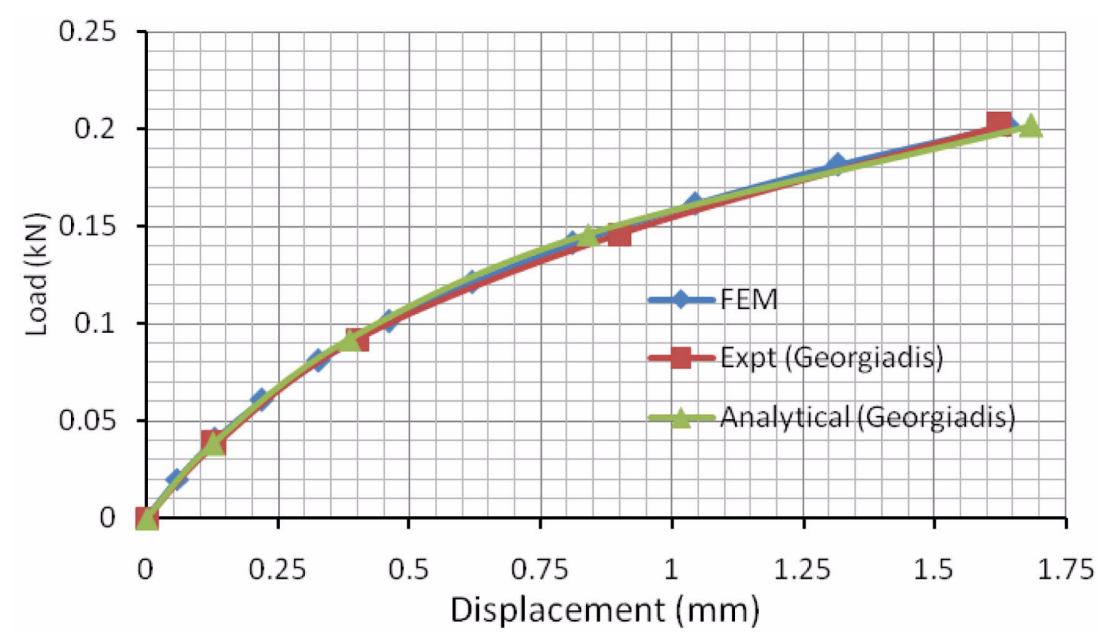

Fig. 7 Load-displacement relation for the purpose of validation

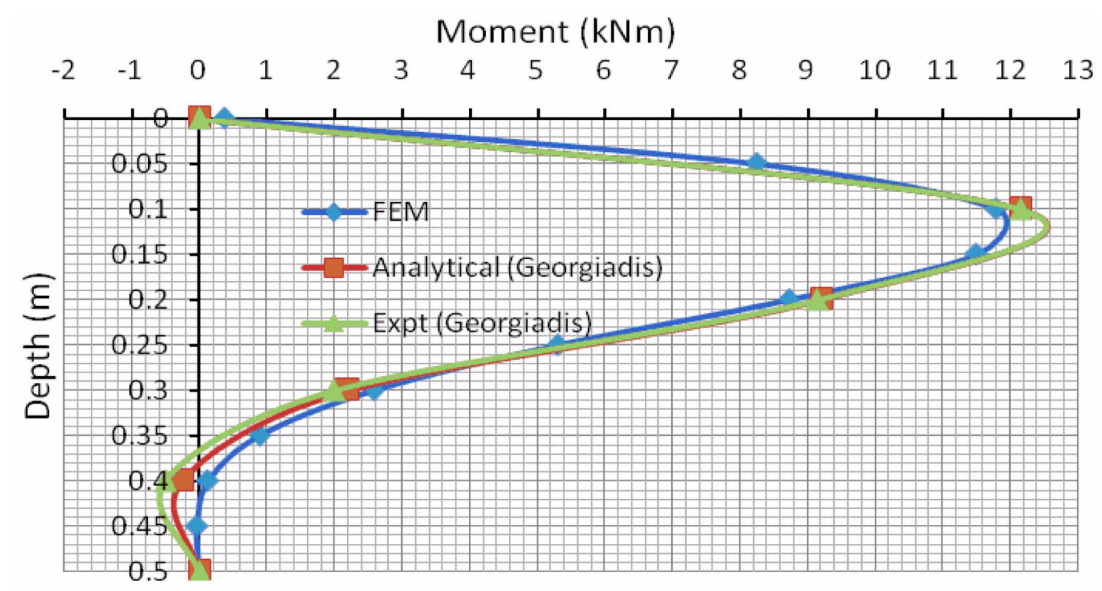

Fig. 8 Distribution of moment along the depth of pile

linear behaviour of the pile by an incremental-iterative procedure.

For the present purposes, the pile was idealized as the beam element and the soil by a number of elasto-plastic sub-element springs attached at each node. To verify the validity of the present procedure, the present results will be compared with those by Georgiadis et al. (1992). The ground deflections obtained at the lateral load of $202 N$ by Georgiadis et al. (1992), Rajashree and Sundaravadivelu (1999) and the present method used are 0.88, 0.77 and $0.84 \mathrm{~mm}$, respectively, which indicates that quite a good agreement is observed among all the three results.

\section{Parametric study}

The two pile groups each consisting of two or three piles are considered. Further, different 




(G2PS)

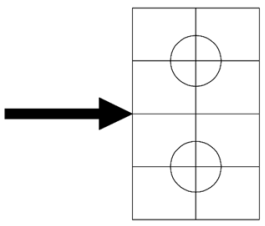

PARALLEL CONFIGURATION (G2PP)

(a)TWO- PILE GROUP

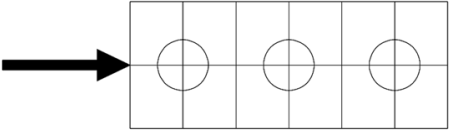

SERIES CONFIGURATION (G3PS)

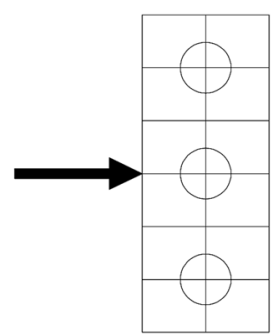

PARALLEL CONFIGURATION (G3PP)

(b)THREE- PILE GROUP

Fig. 9 Different configurations considered in the study

Table 1 Properties of the materials

\begin{tabular}{lc}
\hline \hline \multicolumn{1}{c}{ Pile Size/ Diameter $(D)$} & $300 \mathrm{~mm}$ \\
\hline Length of pile $(L)$ & $3 \mathrm{~m}(3000 \mathrm{~mm})$ \\
Concrete grade used for pile and pile cap & $M-40$ \\
Young's modulus of pile and pile cap $\left(E_{\mathrm{c}}\right)$ & $0.3605 \times 10^{8} \mathrm{kPa}$ \\
Poisson's ratio for concrete $(\mu)$ & 0.15 \\
Young's modulus of elasticity for soil $\left(E_{\mathrm{s}}\right)$ & $4267 \mathrm{kN} / \mathrm{m}^{2}$ \\
Modulus of subgrade reaction $\left(K_{h}\right)$ & $6667 \mathrm{kN} / \mathrm{m}^{3}$ \\
\hline
\end{tabular}

configurations (series and parallel arrangement of piles in the group) are considered for each pile group. In each case, the spacing between the piles is varied from $2 D$ to $5 D$. When the direction of loading is parallel to the line joining the piles, it is referred to as the series arrangement. On the other hand, if the lateral loading is acting in a direction perpendicular to the line joining the piles, it is called the parallel arrangement. Further, the piles are connected at their pile caps of concrete. The pile group is considered to have been embedded in the cohesive soil. Fig. 9 shows various configurations of the pile groups considered for the parametric study.

The properties of the material are given in Table 1. The numerical procedure adopted for analyzing the foundation requires the value of modulus of the subgrade reaction to be given. In absence of a reliable value of this modulus, it has to be carefully selected. According to IS: 29111979, the range of $3200-6500 \mathrm{kN} / \mathrm{m}^{3}$ is recommended for $K_{h}$. Moreover, Tomlinson (1977)

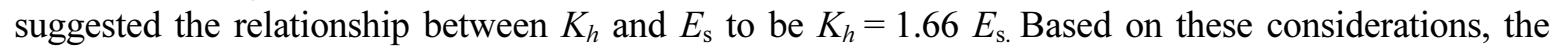
value of $K_{h}$ is assumed to be $6667 \mathrm{kN} / \mathrm{m}^{3}$.

The analysis is carried out for the lateral or vertical load $\left(F_{H}\right.$ and $\left.F_{V}\right)$ of $1000 \mathrm{kN}$ applied on pile cap. The displacements at the top of the pile group and the bending moments in the pile group in 
view of the non-linear behaviour of the soil modeled by the $p-y$ concept are computed for the purpose of comparison. The effect of pile spacing and arrangement of piles in a group on the response of the pile group is considered. Further, the present results of non-linear analysis obtained are compared with those obtained by Chore et al. (2012) based on linear analysis, where the pile was idealized as the one dimensional beam element, the pile cap as two dimensional plate elements, and the soil as linearly elastic independent springs.

\section{Results and discussion}

\subsection{Effect on top displacement}

The displacements at top of the pile groups for either arrangement considered in the present study in view of the non-linear analysis using the $p-y$ curves are given in Tables 2 and 3 for groups of two files and three piles, respectively. The displacements obtained using linear analysis (Chore et al. 2012) are also given in Tables 2 and 3. The percentage increase in displacements owing to nonlinearity of soil is given in Table 4.

For a given configuration, the horizontal displacements computed at the top of the pile group or pile cap are found to decrease with the increase in spacing. The reduction in displacements with the increase in spacing may be attributed to the overlapping of the stressed zones for the case with closer spacings. This further indicates the increase in resistance to lateral loads.

For the series configuration displacement is on higher side in case of the group of two piles as compared to the group of three piles. The lateral resistance of the pile group is found to increase with increase in number of piles for series configuration as indicated by decreasing pile cap displacements. However, for the parallel configuration, slightly different trend is observed with displacements obtained in the context of group of three piles being slightly higher than that obtained in respect of group of three piles which indicates that lateral resistance of pile group is found to

Table 2 Top displacement (mm) for group of two piles due to non-linearity of soil

\begin{tabular}{crrrrrrrr}
\hline \hline Spacing & \multicolumn{1}{c}{$2 D$} & $3 D$ & \multicolumn{1}{c}{$4 D$} & $5 D$ & \multicolumn{1}{c}{$2 D$} & $3 D$ & \multicolumn{3}{c}{$4 D$} & $5 D$ \\
\hline Load $(\mathrm{kN})$ & \multicolumn{3}{c}{ Series arrangement $(G 2 P S)$} \\
\hline 100 & 6.44 & 5.57 & 4.88 & 4.34 & 6.96 & 6.42 & 5.96 & 5.56 \\
200 & 15.93 & 13.30 & 11.34 & 9.90 & 17.47 & 15.56 & 14.06 & 12.84 \\
300 & 28.35 & 23.03 & 19.28 & 16.59 & 31.28 & 27.06 & 23.92 & 21.49 \\
400 & 43.08 & 34.40 & 28.46 & 24.23 & 47.51 & 40.21 & 35.00 & 31.07 \\
500 & 59.42 & 46.96 & 38.55 & 32.63 & 65.23 & 54.43 & 46.88 & 41.28 \\
600 & 76.83 & 60.39 & 49.36 & 41.62 & 83.86 & 69.31 & 59.28 & 51.91 \\
700 & 94.96 & 74.43 & 60.70 & 51.06 & 103.05 & 84.62 & 72.00 & 62.80 \\
800 & 113.59 & 88.911 & 72.425 & 60.86 & 122.62 & 100.22 & 84.97 & 73.90 \\
900 & 132.58 & 103.72 & 84.46 & 70.93 & 142.43 & 116.02 & 98.10 & 85.12 \\
1000 & 151.83 & 118.76 & 96.72 & 81.21 & 162.411 & 131.96 & 111.36 & 96.46 \\
\hline \multicolumn{7}{c}{ Linear Analysis (Chore et al. 2012) } \\
\hline 1000 & 64.41 & 55.75 & 48.78 & 43.39 & 69.65 & 64.23 & 59.58 & 55.57 \\
\hline
\end{tabular}


Table 3 Top displacement (mm) for group of three piles due to non-linearity of soil

\begin{tabular}{|c|c|c|c|c|c|c|c|c|}
\hline Spacing & $2 D$ & $3 D$ & $4 D$ & $5 D$ & $2 D$ & $3 D$ & $4 D$ & $5 D$ \\
\hline Load & \multicolumn{4}{|c|}{ Series arrangement (G3PS) } & \multicolumn{4}{|c|}{ Parallel arrangement $(G 3 P P)$} \\
\hline 100 & 5.85 & 5.09 & 4.53 & 4.13 & 6.97 & 6.68 & 6.31 & 5.94 \\
\hline 200 & 14.35 & 12.08 & 10.48 & 9.38 & 17.47 & 16.17 & 14.86 & 13.68 \\
\hline 300 & 25.57 & 20.95 & 17.81 & 15.68 & 31.30 & 27.30 & 25.13 & 22.73 \\
\hline 400 & 39.13 & 31.44 & 26.32 & 22.88 & 47.52 & 41.42 & 36.54 & 32.64 \\
\hline 500 & 54.46 & 43.22 & 35.80 & 30.84 & 65.24 & 55.83 & 48.66 & 44.00 \\
\hline 600 & 71.04 & 55.95 & 46.02 & 39.38 & 83.88 & 70.86 & 61.24 & 53.91 \\
\hline 700 & 88.47 & 69.37 & 56.82 & 48.40 & 103.07 & 86.27 & 74.11 & 64.95 \\
\hline 800 & 106.50 & 83.30 & 68.03 & 57.79 & 122.64 & 101.95 & 87.18 & 76.15 \\
\hline 900 & 124.94 & 97.60 & 79.59 & 67.47 & 142.45 & 117.82 & 100.40 & 87.48 \\
\hline \multirow[t]{2}{*}{1000} & 143.68 & 112.17 & 91.40 & 77.39 & 162.44 & 133.81 & 113.72 & 98.89 \\
\hline & \multicolumn{8}{|c|}{ Linear Analysis (Chore et al. 2012) } \\
\hline 1000 & 58.51 & 50.92 & 45.27 & 41.25 & 69.66 & 66.76 & 63.12 & 59.42 \\
\hline
\end{tabular}

Table 4 Percentage increase owing to non-linearity of soil at different pile spacing

\begin{tabular}{cccccccc}
\hline \hline $2 D$ & $3 D$ & $4 D$ & $5 D$ & $2 D$ & $3 D$ & $4 D$ & $5 D$ \\
\hline \multicolumn{7}{c}{ Group of two piles } \\
\hline \multicolumn{7}{c}{ Series arrangement (G2PS) } \\
135.73 & 113.02 & 98.27 & 87.18 & 133.19 & 105.46 & 86.89 & 73.59 \\
\hline \multicolumn{8}{c}{ Group of three piles } \\
\hline \multicolumn{7}{c}{ Series arrangement (G3PS) } \\
145.59 & 120.28 & 101.89 & 87.59 & 133.21 & 100.42 & 80.16 & 66.42 \\
\hline
\end{tabular}

decrease with increase in number of piles for parallel configuration.

Further, the displacements computed for the parallel arrangement are observed to be higher as compared to those obtained for the series configuration for either group considered, i.e., group of two piles and group of three piles. The trend of the displacements observed as above in respect of spacing, number of piles in a group and configuration of the arrangement is similar to that observed from the linear analysis of the same system using a simplified model (Chore et al. 2012).

The non-linear behaviour of soil is found to increase the top displacement of the group at any pile spacing and for any configuration as compared to the displacements obtained by assuming the soil to be linear (Chore et al. 2012). The maximum increase in the displacement is found to be $136 \%$, while minimum increase is observed to be $74 \%$ for group of two piles. The corresponding values are observed to be $145 \%$ and $66 \%$ for group of three piles.

\subsection{Capacity of the pile group}

The capacity of the pile groups with various arrangements is evaluated by the non-linear analysis with the soil assumed to behave in the non-linear fashion. The load corresponding to a displacement 


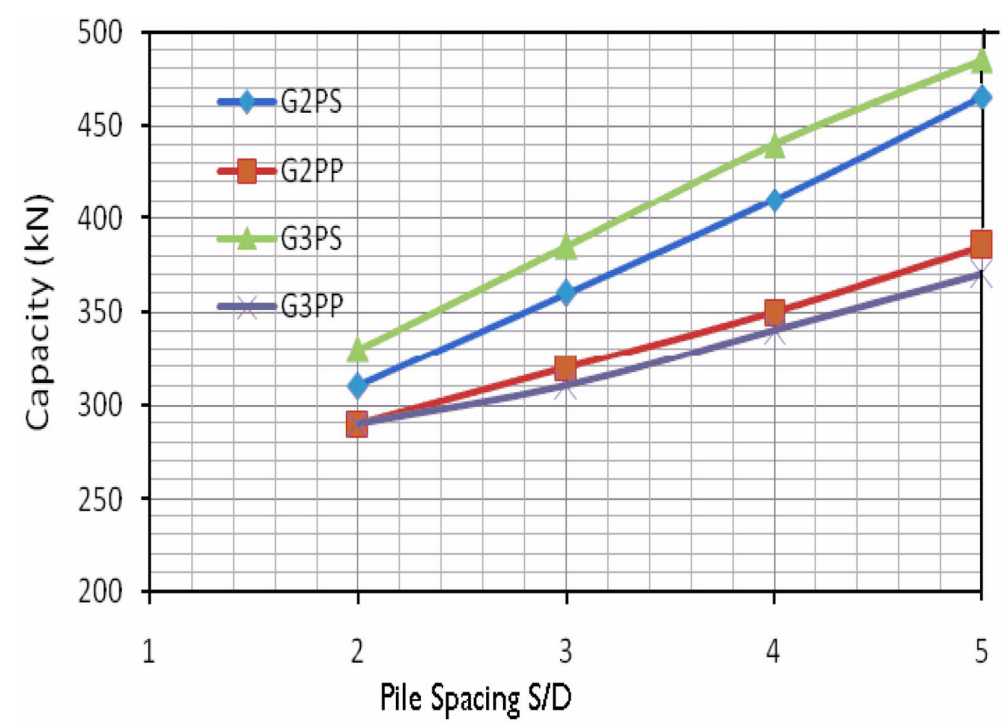

Fig. 10 Capacity of the pile group

of $10 \%$ of the pile diameter is referred to as the capacity of the pile group. Fig. 10 shows the capacity of the group for various configurations considered in the present study.

It is observed that the capacity of the pile group increases with spacing. The capacity is further found to increase with the increase in the number of piles for the series configuration. However, for the parallel arrangement of the piles in a group, exactly opposite trend is observed even though the capacity at a smaller pile spacing such as $2 D$ is the same for the groups with two or three piles. The highest capacity is observed for group of three piles with the series arrangement, followed by group of two piles with the series arrangement, and subsequently, by group of two piles with the parallel configuration. The group of three piles (parallel arrangement) offers the lowest capacity.

\subsection{Effect on maximum moment in piles}

The maximum moment developed in the piles owing to the non-linear behaviour of soil is studied. The fixed end moments are found to increase with spacing irrespective of the number of piles in a group for the series arrangement. The fixed end moments are on the higher side for group of three piles as compared to those observed for group of two piles, the difference being in the range of $63 \%$ to $76 \%$.

The positive moments are found to decrease with spacing for the pile group with the parallel arrangement of piles therein. The positive moments for group of three piles are on the higher side as compared to those for group of two piles. The increase in positive moment for group of three piles is in the range of $0.3 \%-0.55 \%$, when compared with the moment for group of two piles.

\subsubsection{Comparison with maximum moment for linear analysis}

The maximum moment developed in the piles of various pile groups using the linear or non-linear analysis, along with the percentage difference, are compared in Tables 5 and 6 , for group of two and three piles, respectively. 
Table 5 Maximum moment $(\mathrm{kN}-m)$ and percentage variations for group of two piles

\begin{tabular}{crrrrrrrr}
\hline \hline Pariculars & \multicolumn{3}{c}{ Series arrangement [G2PS] } & \multicolumn{3}{c}{ Parallel arrangement [G2PP] } \\
\hline Spacing & $2 D$ & $3 D$ & $4 D$ & $5 D$ & $2 D$ & $3 D$ & $4 D$ & $5 D$ \\
Nonlinear & -68 & -104 & -138 & -167 & 62 & 58 & 54 & 51 \\
Linear (Chore et al. 2012) & -69 & -120 & -166 & -197 & 140 & 129 & 119 & 111 \\
\% decrease & 2 & 13 & 16 & 15 & 56 & 55 & 54 & 54 \\
\hline
\end{tabular}

Table 6 Maximum moment $(\mathrm{kN}-m)$ and percentage variations for group of three piles

\begin{tabular}{crrrrrrrr}
\hline \hline Pariculars & \multicolumn{3}{c}{ Series arrangement [G3PS] } & \multicolumn{3}{c}{ Parallel arrangement [G3PP] } \\
\hline Spacing & $2 D$ & $3 D$ & $4 D$ & $5 D$ & $2 D$ & $3 D$ & $4 D$ & $5 D$ \\
Nonlinear & -119 & -183 & -237 & -274 & 62 & 58 & 55 & 52 \\
Linear (Chore et al. 2012) & -145 & -230 & -287 & -322 & 140 & 134 & 126 & 119 \\
\% decrease & 18 & 20 & 17 & 15 & 56 & 57 & 57 & 56 \\
\hline
\end{tabular}

A comparison based on the two tables indicates that by incorporating the effect of non-linear behaviour of soil, the moments are found to decrease. For the fixed end moment, the maximum decrease is observed to be $20 \%$, while the minimum decrease is $2 \%$. In respect of positive moment, the maximum decrease is observed to be $57 \%$ and the minimum decrease is $54 \%$.

Further, the effect of non-linearity of soil is found to be significant for the series arrangement. For the group of two piles, the percentage decrease in the fixed end moments is observed to be comparatively less than that for group of three piles, particularly for the pile spacing of $2 D$ to $4 D$. However, for the pile spacing of $5 D$, the percentage decrease is observed to be on the higher side for group of two piles as compared to that for group of three piles. In respect of the positive moment, the percentage decrease is on the higher side for group of three piles as compared to that for group of two piles. However, the variation is not that significant.

\section{Conclusions}

Some general conclusions emerging from the analysis of the pile foundation studied in this paper are summarized below:

(1) The various parameters such as spacing between the piles, number of piles in a pile group and arrangement of piles in a group significantly affects the behaviour of the pile group.

(2) With the increase in pile spacing, the lateral resistance of the pile group is found to increase.

(3) The lateral resistance of the pile group is found to increase with the increase in the number of piles for series configuration, but it is found to decrease with the increase in the number of piles for parallel configuration.

(4) The piles in a group with the series arrangement exhibit greater lateral resistance than those in the parallel arrangement.

(5) The nonlinearity of soil behaviour decreases the lateral resistance of pile group.

(6) The maximum increase in the displacement of the pile top is found to be $145.6 \%$, while the minimum increase is observed to be $66.4 \%$ due to inclusion of the non-linearity of the soil behaviour. 
(7) The capacity of the pile group increases with pile spacing. The capacity is found to increase with the increase in the number of piles for the series arrangement and to decrease for the parallel arrangement.

(8) The fixed end moments are found to increase, while the positive moments are found to decrease with the increase in pile spacing. The moments are on the higher side for the group of three piles as compared to those for the group of two piles.

(9) The incorporation of the nonlinear behaviour of soil decreases the fixed end moments in all the pile groups considered in the study. The fixed end moment is found to decrease in the range of $2 \%$ to $20 \%$, while the positive moment in the range of $54 \%$ to $57 \%$.

\section{References}

Banerjee, P.K. and Davis, T.G. (1978), "The behaviour of axially and laterally loaded single piles embedded in non-homogeneous soils", Geotechnique, 28(3), 309-326.

Broms, B.B. and Choa, V. (1998), "Design of laterally loaded piles in cohesive soils using p-y curves", Soils Found., 38(2), 17-26.

Chiou, J.S. and Chen, C.H. (2007), "Exact equivalent model for a laterally loaded linear pile-soil system", Soils Found., 47(6), 1053-1061.

Chore, H.S., Ingle, R.K. and Sawant, V.A. (2010), "Parametric study of pile groups subjected to lateral loads", Struct. Eng. Mech., 26(2), 243-246.

Chore, H.S. Ingle, R.K. and Sawant, V.A. (2012), "Parametric study of laterally loaded pile groups using simplified F.E. models", Coupled Syst. Mech., 1(1) (In Press, to be published by March 2012).

Desai, C.S. and Abel, J.F. (1974), Introduction to finite element method, CBS Publishers, New Delhi, India.

Desai, C.S. and Appel, G.C. (1976), "3-D Analysis of laterally loaded structures", Proc. 2nd Int. Conf. on Numer. Meth. Geomech.-ASCE, (1), 405-418.

Desai, C.S., Kuppusamy, T. and Alameddine, A.R. (1981), "Pile cap-pile group-soil interaction", J. Struct. Eng.-ASCE, 107(5), 817-834.

Dewaikar, D.M. and Patil, P.A. (2006), “Analysis of a laterally loaded pile in cohesion-less soil under static and cyclic loading", Indian Geotech. J., 36(2)

Dewaikar, D.M., Verghese, S., Sawant, V.A. and Chore, H.S. (2007), "Non-linear 3-D FEA of laterally loaded pile group incorporating no-tension behaviour of soil", Indian Geotech. J., 37(3), 174-189.

Dewaikar, D.M., Salimath, R.S. and Sawant, V.A. (2009), "A modified p-y curve for the analysis of a laterally loaded pile in stiff clay", J. Australian Geomech., 44(3), 91-100.

Dewaikar, D.M., Chore, H.S., Goel, M.D. and Mutgi, P.R. (2011), "Lateral resistance of long piles in cohesive soils using p-y curves", J. Struct. Eng.-ASCE, 38(3), 222-227.

Georgiadis, M. and Butterfield, R. (1982), "Laterally loaded pile behaviour", J. Geotech. Eng.-ASCE, 108(1), 155-165.

Geogiadis, M. (1983), "Development of p-y curves for layered soils", Proc. Conference on Geotechnical Practice in Offshore Engineering, University of Texas, Austin, 536-545.

Georgiadis, M., Anagnostopoulos, C. and Saflekou, S. (1992), "Cyclic lateral loading of piles in soft clay", Geotech. Eng., 23(1), 47-60.

Kim, Youngho, Jeong, Sangseom and Won, Jinoh (2009), "Effect of lateral rigidity of offshore piles using proposed p-y curves in marine clay", Mar. Georesour. Geotec., 27(1), 53-77.

Kim, Youngho, Jeong, Sangseom and Lee, Sungjune (2011), "Wedge failure analysis of soil resistance on laterally loaded piles in clay", J. Geotech. Geoenviron., 137(7), 678-694.

Kodikara, J., Haque, A. and Lee, Kag Ying (2010), "Theroratical p-y curves for laterally loaded single piles in undrained clay using bezier curves", J. Geotech. Geoenviron., 136(1), 265-268

Matlock, H. and Reese, L.C. (1960), "Generallized solutions for laterally loaded piles", J. Soil Mech. Found. Eng.-ASCE, 86(5), 63-91. 
Matlock, H. (1970), "Correlations for design of laterally loaded piles in soft clay", Proc. 2nd Offshore Technology Conference, Houston, 1, 577-594.

Mocwa, R.L. and Duncan, J.M. (2001), "Lateral loaded pile group effects and p-y multipliers", ASCE Geotech., 113, 728-742.

Poulos, H.G. (1971), "Behaviour of laterally loaded piles: II-group of piles", J. Soil Mech. Found. Eng., 97(5), 733-751.

Rajashree, S.S. and Sundaravadivelu, R. (1999), "Gap mpdel of one way cyclic lateral load on vertical piles in soft clay", Proc. International Conference on Offshore and Nearshore Geotechnical Engineering (GEO Shore), ONGC Panvel, New Mumbai (India), 295-300.

Reese, L.C. and Matlock, H. (1956), "Non-dimensional solutions for laterally loaded piles with soil modulus assumed proportional to depth", Proc. 8th Texas Conference on Soil Mechanics and Foundation engineering, Bereau of Engineering Research, University of Texas, Special Publication 29

Reese, L.C., Cox, W.R. and Koop, F.D. (1974), "Analysis of laterally loaded piles in sand", Proc. Offshore Technology Conference, 2080, 472-483.

Sawant, V.A., Amin, N.B. and Dewaikar, D.M. (1996), "Response of a pile to cyclic lateral loads using moment area method", Indian Geotech. J., 26(4), 353-363.

Winkler, E. (1867), "Die lehrevon elastizitat und festigkeit (On elasticity and fixity)", Prague, 182. 